\title{
Research Paper \\ The Position of a Curriculum based on the Multiple Intelligences in the Textbooks of the First Grade of Primary School based on the Components of Multiple Intelligences
}

\author{
Akbar Soltani ${ }^{1}$, Yosef Adib ${ }^{* 2}$, Firooz Mahmoodi ${ }^{3}$, Sharam Vahedi ${ }^{2}$ \\ 1. Ph.D. in Curriculum Planning, Faculty of Education and Psychology, University of Tabriz, Iran \\ 2. Professor, Department of Educational Sciences, Faculty of Education and Psychology, University of Tabriz, Iran \\ 3. Associate Professor, Department of Educational Sciences, Faculty of Education and Psychology, University of Tabriz, Iran
}

Citation: Soltani S, Adib Y, Mahmoodi F, Vahedi S. The position of a curriculum based on the multiple intelligences in the textbooks of the first grade of primary school based on the components of multiple intelligences. Quarterly Journal of Child Mental Health. 2020; 7(1): 270280 .

\section{http://dx.doi.org/10.29252/jcmh.7.1.23}

\section{A R T I C L E I N F O}

Keywords:
Multiple intelligences,
curriculum,
textbooks of the first
grade

Received: 12 Jul 2018

Accepted: 17 Nov 2018

Available: 20 Jun 2020

\section{A B S T R A C T}

Background and Purpose: A valid curriculum must be based on the accurate understanding of the psychological dimensions of human beings. One of the most important mental aspects closely related to learning process and curriculum is the concept of intelligence. The concept of intelligence has evolved from a single concept to a multidimensional one with many forms. In this regard, Gardner's theory of multiple intelligences (2011) has established new conditions for understanding human intelligence and creating strong perspectives in the process of education and has significant functions in education. This study aimed to determine the position of multiple intelligences in the curriculum of the first grade of primary school.

Method: The methodology of this research was descriptive content analysis using the method of Shannon's Entropy (1984) which has a new view on the quantitative data process. Based on this method, known as the compensatory model, the content of the first grade textbooks was examined based on 9 principal components and 55 sub-components of multiple intelligences. The statistical population of this study included all textbooks of the first grade of primary school (4 books), all of which, as a census, were selected as the study sample. A researcher-made checklist based on multiple intelligence components (Gardner, $2011 \&$ Flithem, 2014) was used as the study tool.

Results: The results of content analysis based on the Shannon Entropy method showed that logical mathematical intelligence with 573 items had the maximum frequency while musical intelligence with no item had the minimum frequency among the components. The coefficient of significance was 0.127 for logical mathematical intelligence and 0 for musical intelligence.

Conclusion: Little or no attention was paid to some components of multiple intelligences in the textbooks of the first grade. However, multiple intelligences are important factors in learning progress. Accurate design and implementation of the curriculums in the form of multiple intelligences can make the individual differences to be noticed and can prevent the academic failure of the students.

\footnotetext{
* Corresponding author: Yosef Adib, Professor, Department of Educational Sciences, Faculty of Education and Psychology, University of Tabriz, Iran.

E-mail addresses: Yousef_adib@yahoo.com
} 


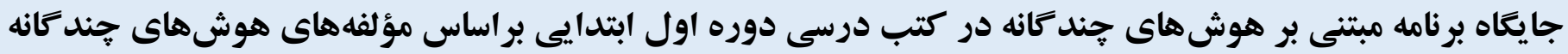

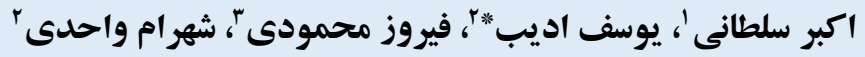

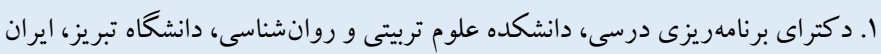

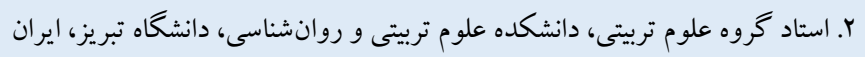

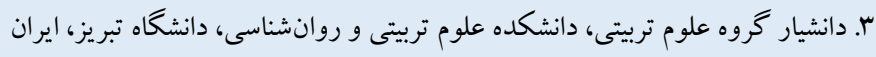

زمينه و هدف: يكك برنامه درسى معتبر بايد مبتنى بر دركك صحيح و دقيق ابعاد روانشناختى انسان باشد. از جمله جنبه هاى روانى مهم انسان

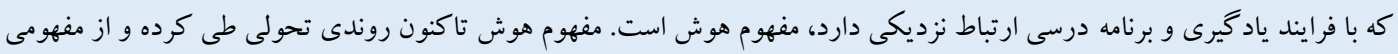

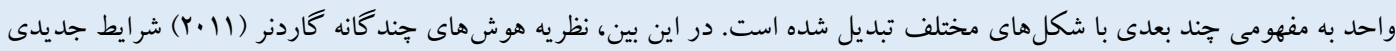

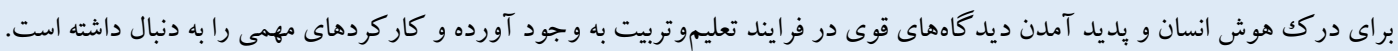

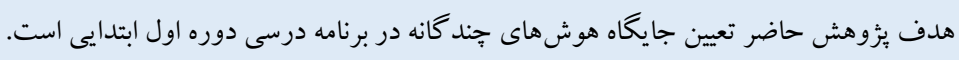

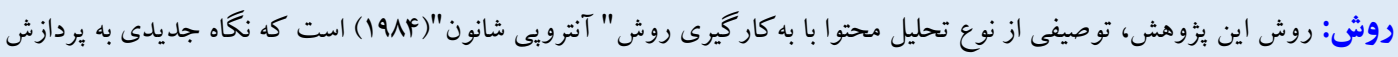

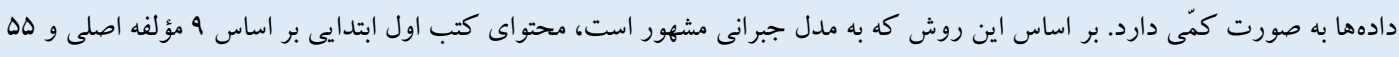

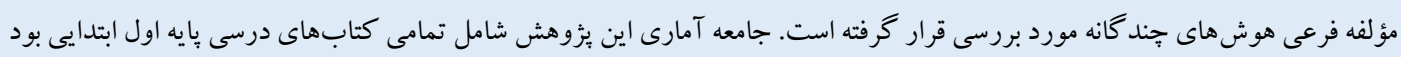

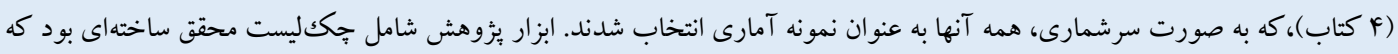

$$
\text { بر اساس مؤلفههاى هوش هاى جند كانه (كاردنر، }
$$

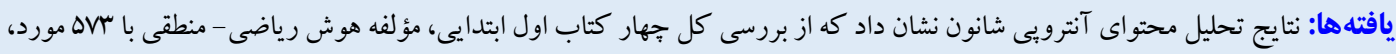

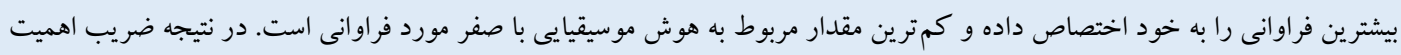

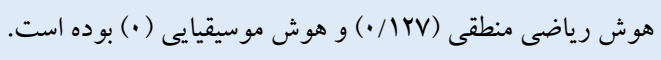

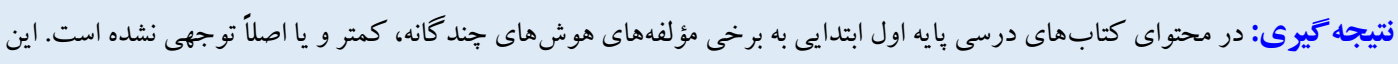

دريافت شده:

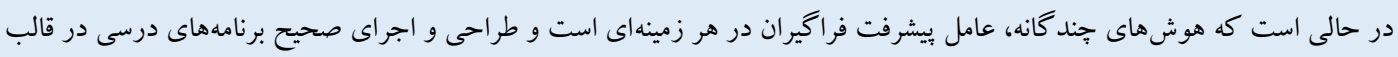

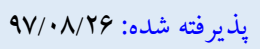

هوش هاى جند گانه مىتواند تفاوتهاى فردى فراگير ان را به خوبى مورد توجه قرار دهد و مانع افت تحصيلى دانش آموزان شود.

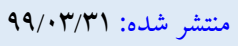

* نويسنده مسئول: يوسف اديب، استاد گروه علوم تربيتى، دانشكده علوم تربيتى و روانشناسى، دانشكاه تبريز، ايران.

Yرايانامه: Yousef_adib@yahoo.com

تلفن: FI-Mrrar.Vr 
مر اتب خاصسى را در بين اين عوامل مطرح نمى كند. با شــناسـايى اين

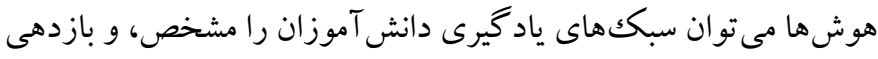

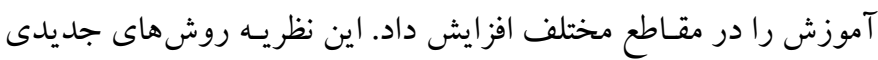

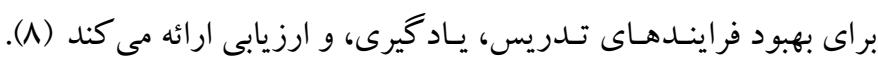

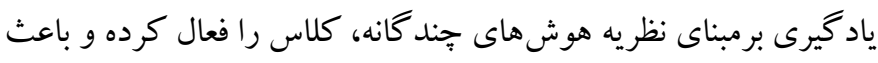

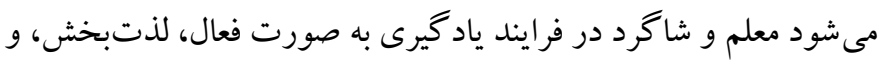

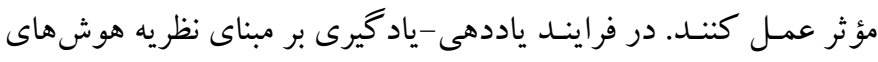

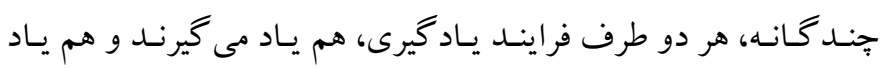

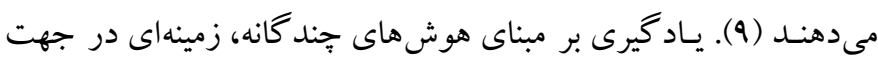

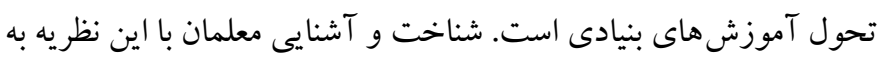

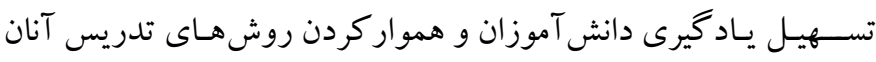

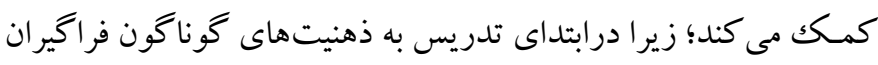

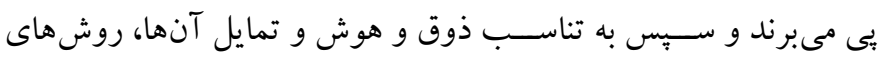

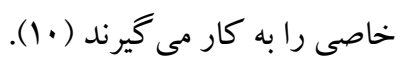

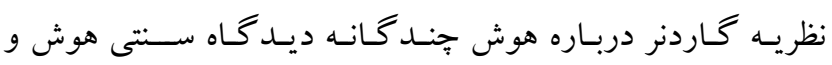

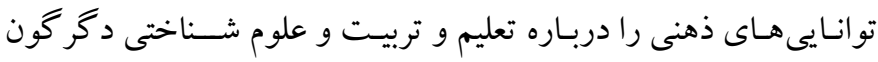
ساخته و روشها و برنامه هاى آموزشى را تحت تأثير قرار داده است (r).

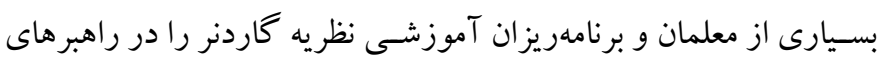

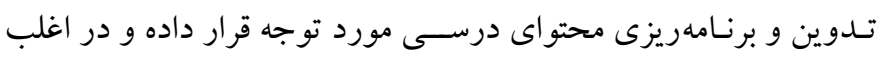

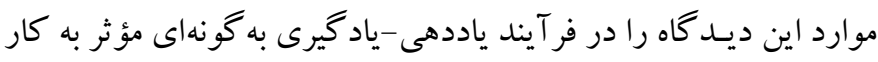

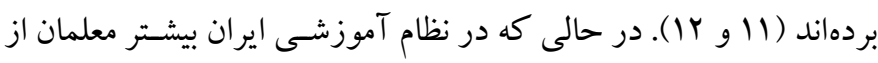

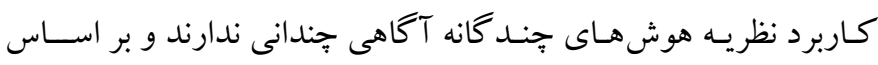

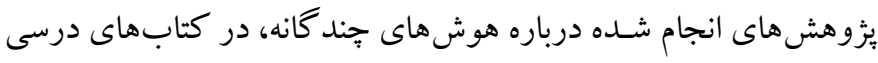
به طور متوازن به همه هوش ها توجه كافى نشده است؛ به طورى كه توجه

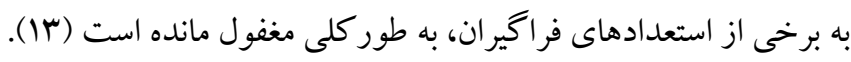

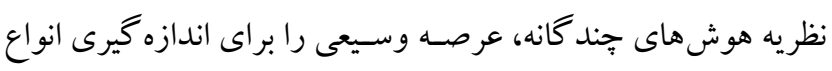

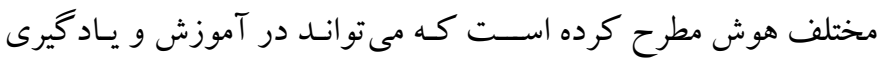

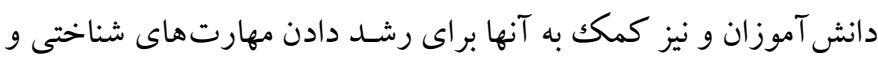

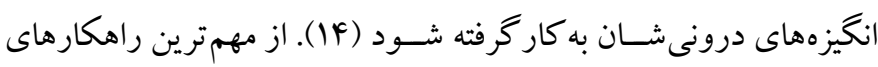

6. Intrapersonal In

7. Interpersonal

8. Spiritual

9. Naturalistic

10. Existential
در طى سـالهاى اخير روانشـناسـان به منظور يافتن ياسـخ براى سؤ الاتى

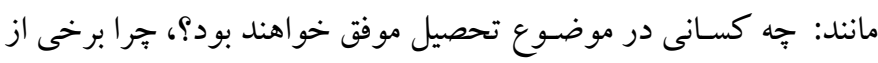

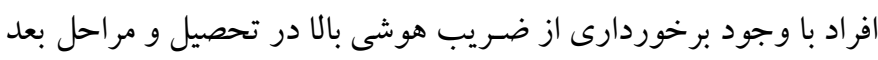

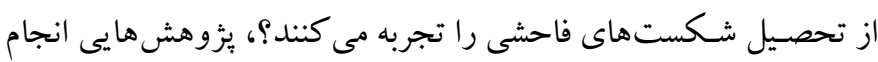

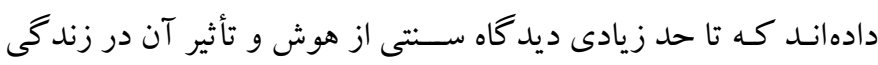
انسـان را تغيير داده است (1). هوش يكى از سرمايههاى بى بدليل انسانها اســت و از همان زمانى كه روانشــناسـان به تشــخيص و ارزيابى آن

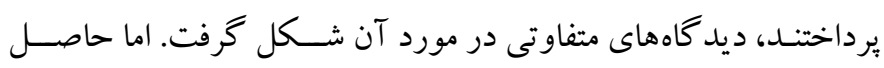

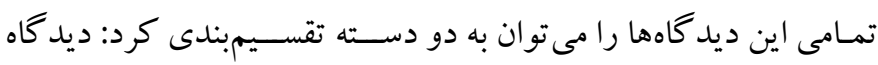

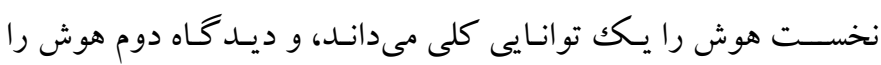

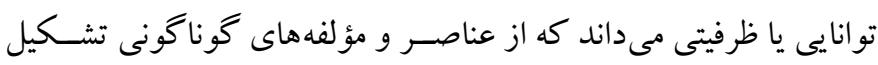

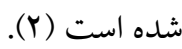

يكى از كســانى كـه هوش را مجموعـهاى ازجنـدين عـامل مى داند،

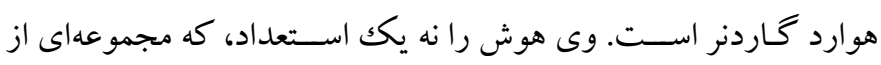

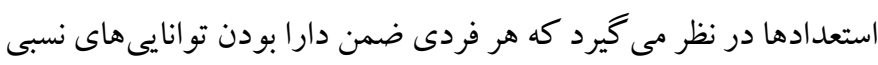
در تمـام مؤلفهها، در يكى از آنها زبدهتر اســت. اين نظريه كار كردهاى

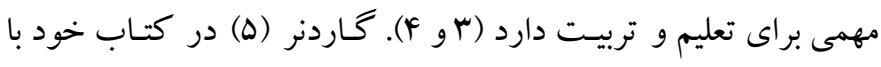
عنوان جـارجوب هــاى ذهن، هوش را به عنوان توانايى زيســى - روانى

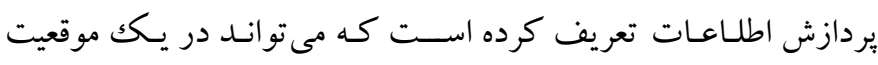

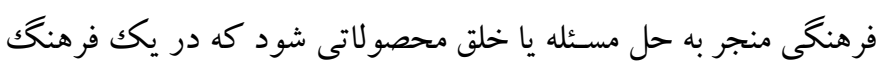

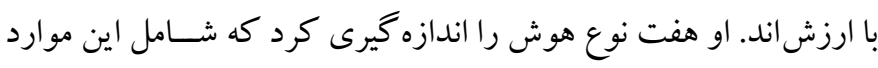

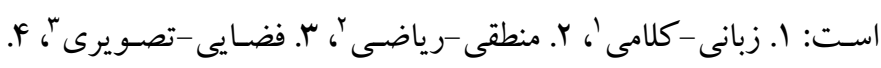

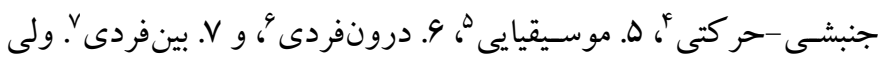

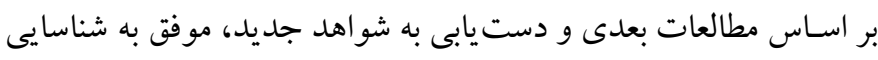

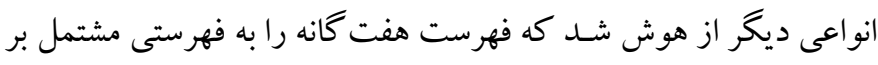

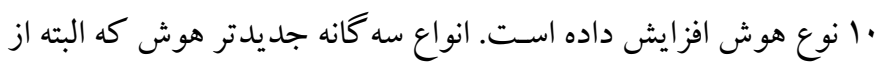

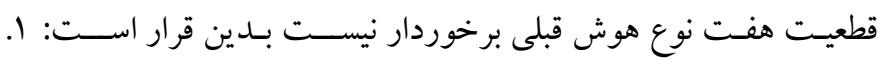

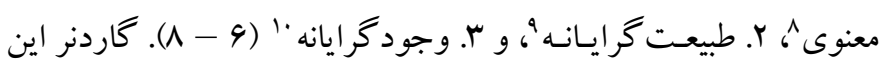

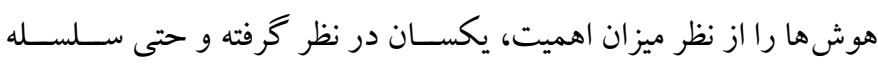

1. Linguistic

2. Logico-mathematical

3. Spatial

4. Kinesthetic

5. Musical 
موظفاند، ضـمن طرح كردن تصـويرى وسـيع، بربار و دقيق از آينده،

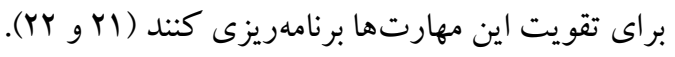

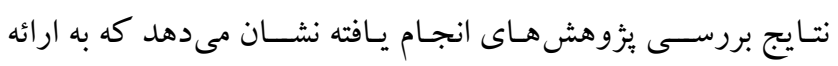

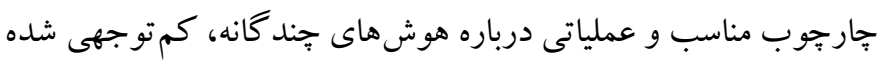

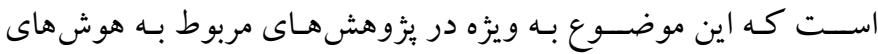

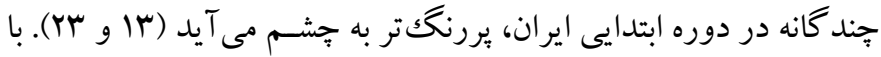

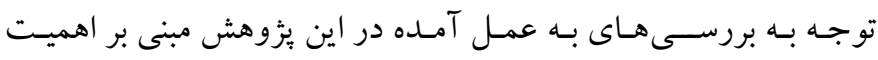

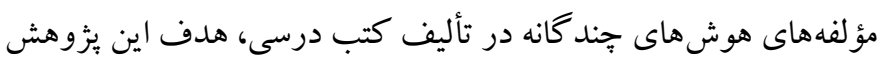

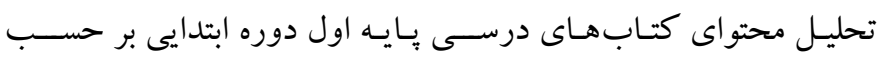

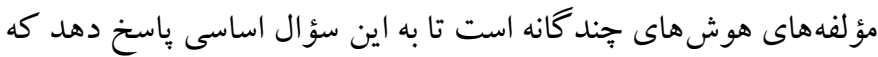

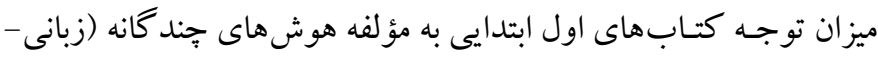

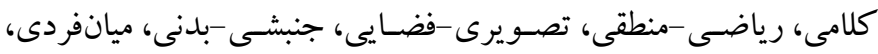

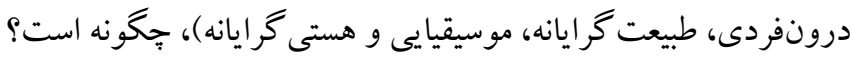

\section{الف) طرح يخوهش و شر كت كنند}

روش اين بزوهش، توصـيفى از نوع تحليل محتوا اســت. تحليل محتوا

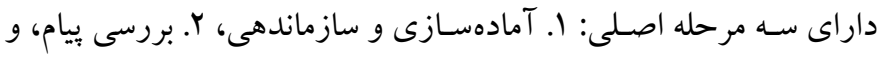

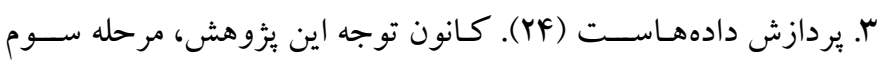

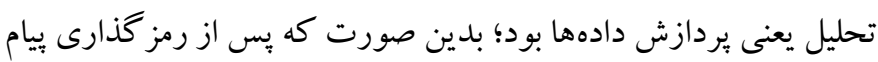

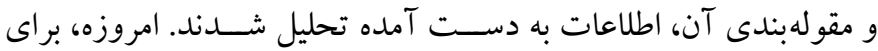
تحليل دادهها روشهاى بسيارى ارائه شده كه اساس آنها درصدگيرى از

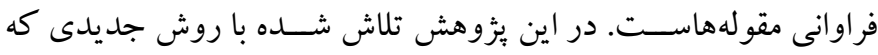

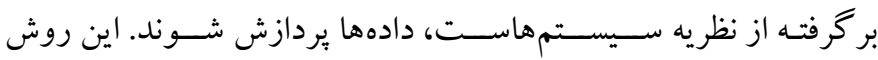

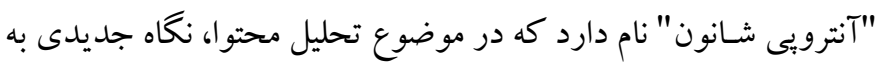
يردازش دادهها دارد. بر اسـاس اين روش، تحليل دادهها بسـيار قوىتر و

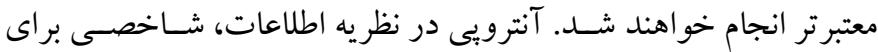
انـدازه گيرى عـدم اطمينان اســت كه به وســــله يكك توزيع احتمال بيان مىشـود. بر اسـاس اين روش كه به مدل جبرانى مشـهور اسـت، محتواى

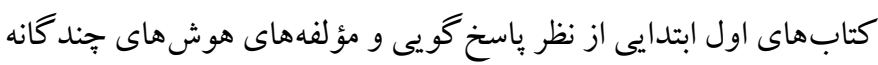
و ها شـاخص طبقبندى شـده، مورد بررسـى قرار كرفته اسـت. در اين
اجراى هوشهـاى جنـدگَانه در دنياى واقعى، گنجاندن آنها در محتواى برنامههاى درسى است. يكى از مهم ترين برنامه درسى در كشور ما، برنامه

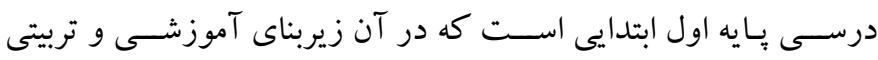

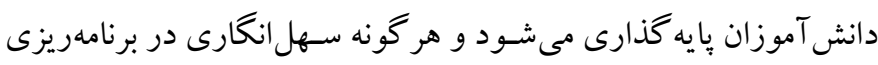

نو آموزان، صدمات جبر اننايذيرى به بيكره اجتماع وارد خو اهد كردي دهرد

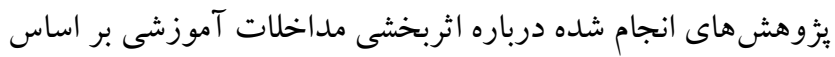

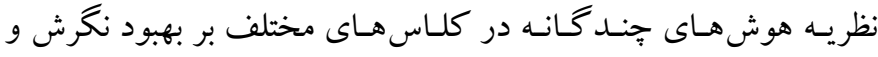

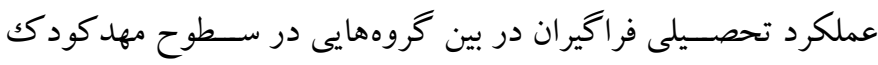

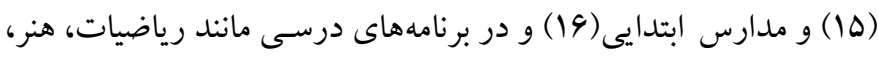
جغر افيا، و علوم تجربى(IV) حكايت دارد. اسـتجى و نفيسسى (IN) در بـ (IN ئزوهشى براى شـناسـايى هوش هاى غالب در كتاب درسى (Bricks1) فنلاند، نشان داد كه هوش هاى كلامى، درونفردى و بين فردى، هوش هاى

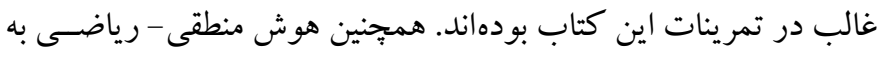

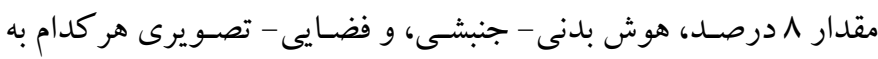

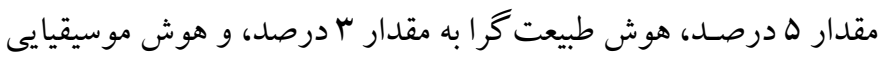
به مقدار Y درصد در اين كتاب مورد توجه قرار كرفتهاند. بر مبناى شواهد و مستندات موجود (19)، در نظام برنامهريزى درسى

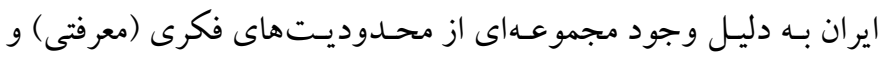

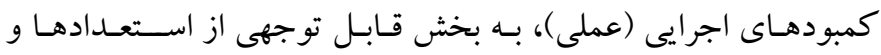
قابليت هاى هوشى دانش آموزان توجه نشـده اسـت. در واقع آنجه كه در

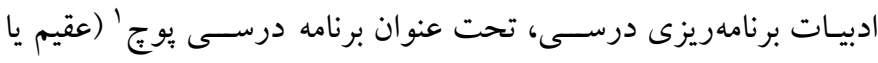

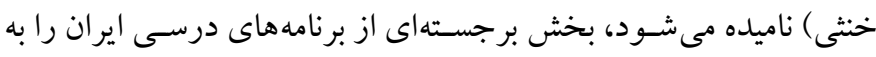

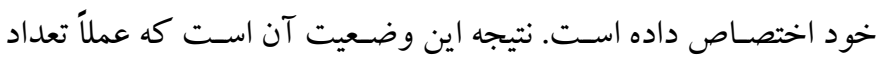
زيادى از قلمروهاى برنامه درسى كه در رشد و يرورش موزون، متعادل،

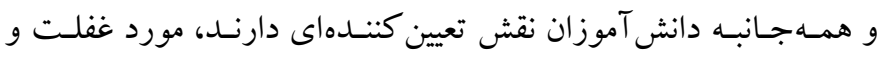

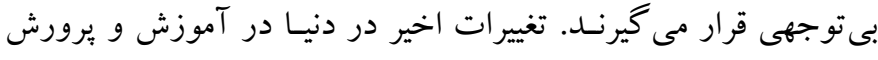

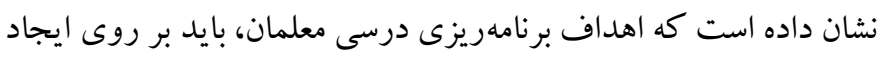

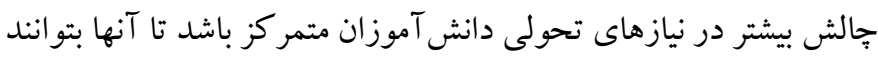

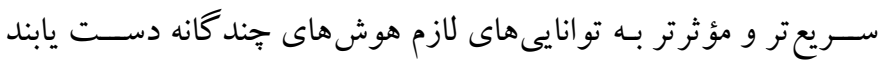

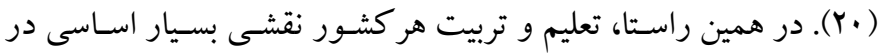

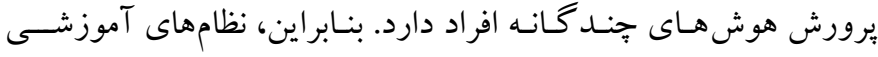


اسـت. مؤلفهها و شـاخص هاى حاصـل در جدول اكزارش شـده اسـت.

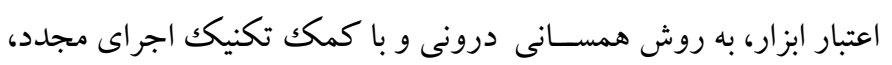

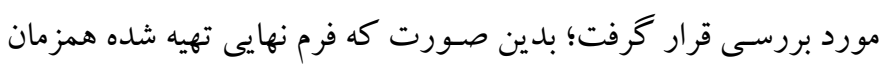

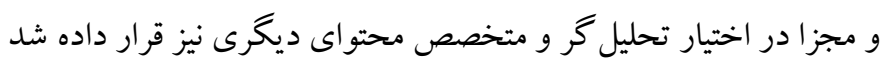

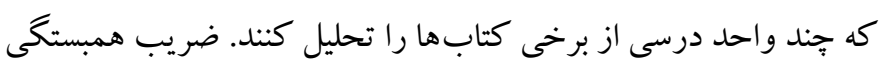

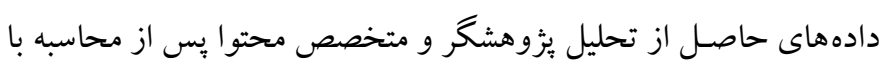

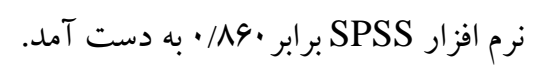

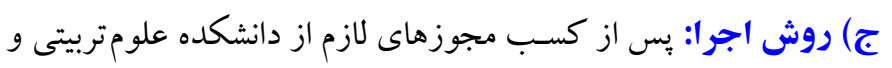

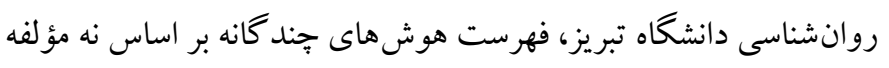

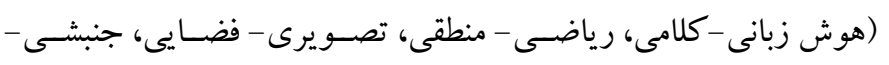

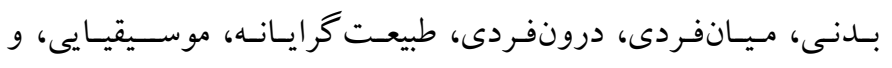

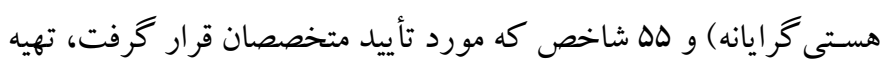

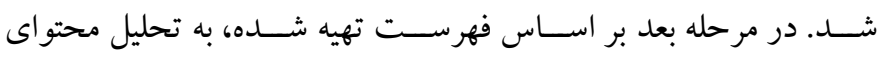

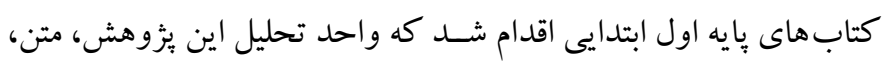

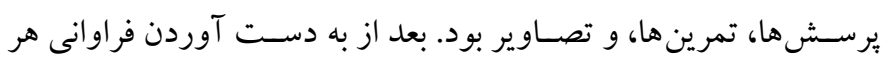

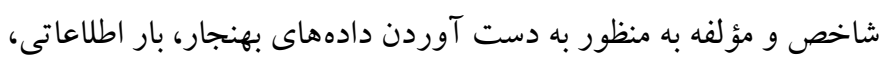

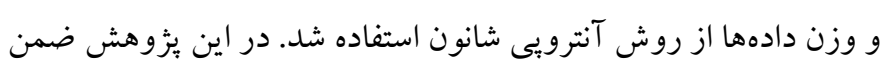

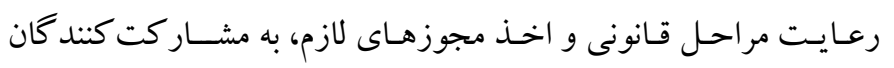
(معلمان، سر گروههاى درسى و متخصصان) اطمينان داده شد كه نتايج

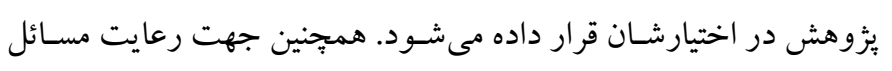
اخلاقى، مشخصات آنها افشا نخو اهد شد.

يافته ها

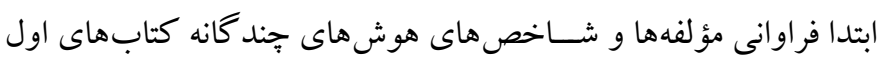

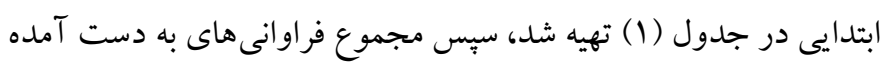
بر حسب هر مؤلفه در جدول r جمع بندى شد، و در نهايت دادههاى اين

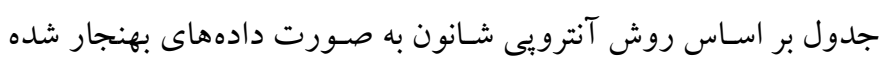

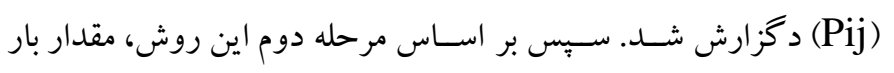

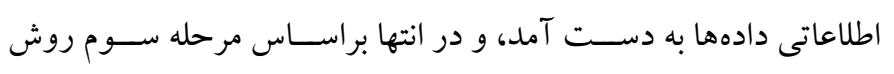

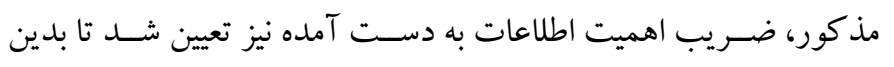

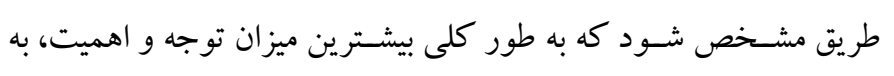

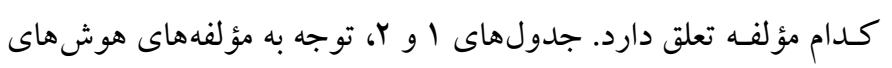

روش ابتدا ييام برحسب مقوله ها به تناسب هر ياسخگگ در قالب فراوانى، شـمارش شـده و بر اساس دادههاى جدول فراوانى مر احل، به اين ترتيب

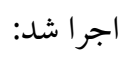
مرحلـه اول: مـاتريس هـاى جـدول فراوانى بهنجار شــــه از رابطه زير به دست Tمد: $P i j=\frac{F i j}{\sum_{i=1}^{m} F i j} \quad(i=1,2,3, \ldots, m, j=1,2 \ldots, n)$

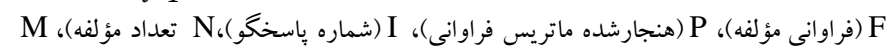

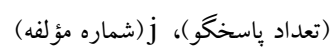
مرحله دوم: محاسبه بار اطلاعاتى هر مقوله و قرار دادن آن در ستونهاى آنهار مربوطه از رابطه زير به دست آمد: $\mathrm{Ej}=\mathrm{k} \sum_{i=1}^{m}\left[\mathrm{p}_{\mathrm{ij}} \ln \mathrm{p}_{\mathrm{ij}}\right]$ $(\mathrm{i}=1,2,3, \ldots, \mathrm{m}, \mathrm{j}=1,2 \ldots, \mathrm{n}) \quad \mathrm{k}=\frac{1}{\operatorname{Ln} M}$

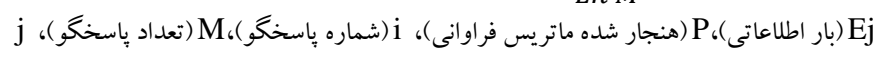

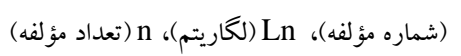

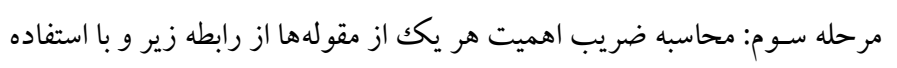

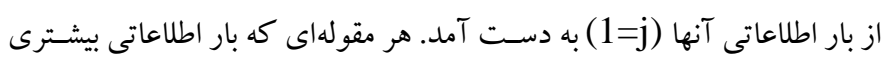

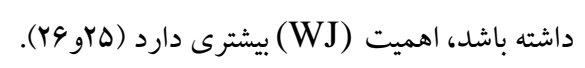
$\mathrm{Wj}=\frac{E j}{\sum_{j=1}^{m} E j}$

Ej (باراطلاعاتى)، Wj Ej (درجه اهميت)، j (شماره مؤلفه)، N (تعداد مؤلفه)

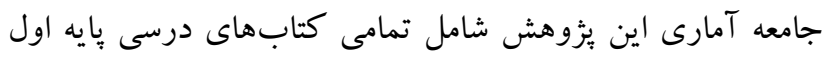

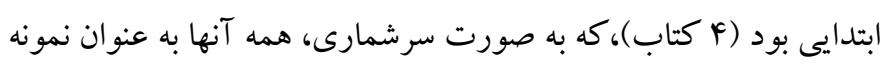
آمارى انتخاب شدند.

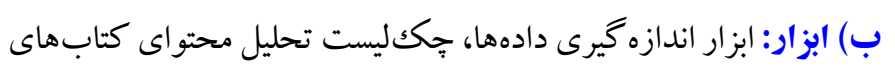

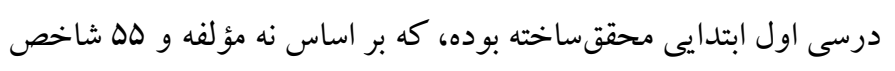

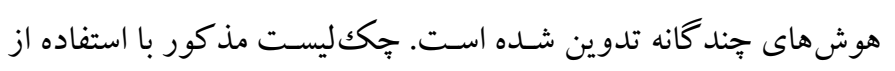

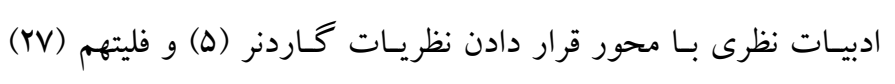

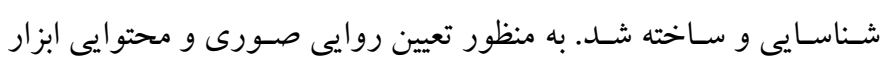

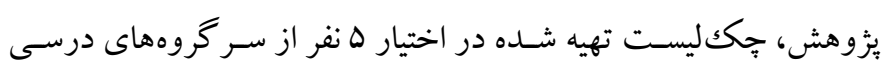

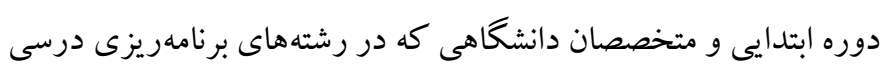

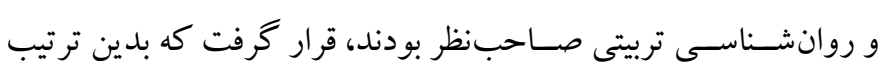

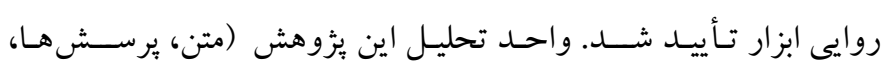

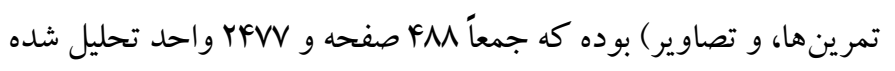


بِايه اول ابتدايى را به صــورت كلى با زيرمؤلفههاى مربوط به هريكك از هوشهاى جند گانه نشان مىدهد.
جند كانه را به تفكيك فراوانى هر مؤلفه و به صورت كلى نشان مىدهند.

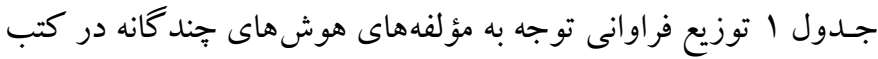

جدول ا: توزيع فراوانى توجه به مؤلفهاى هوشهاى جندكانه در كتب بايه اول ابتدايع

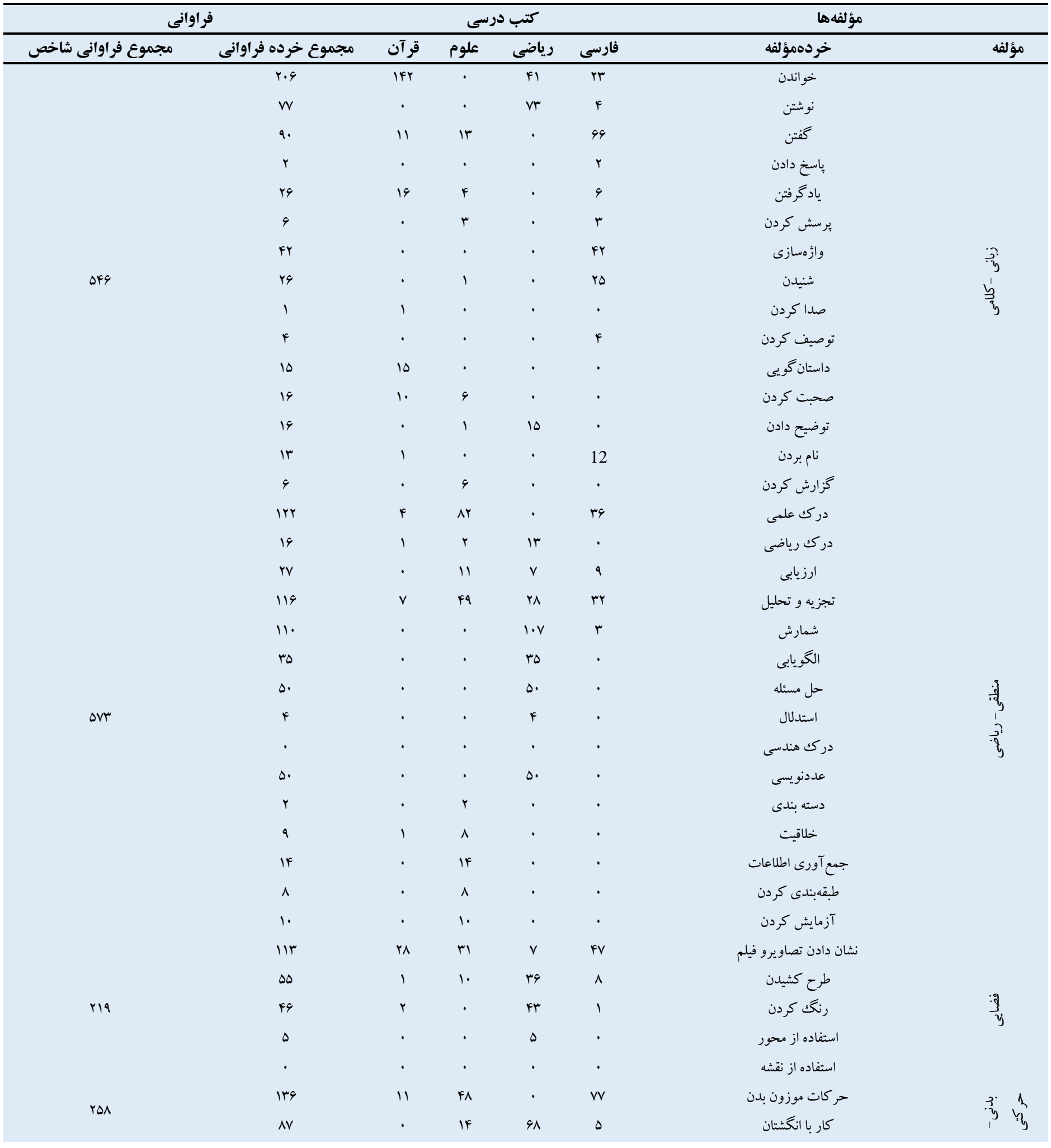




\begin{tabular}{|c|c|c|c|c|c|c|c|}
\hline & ו & $r$ & 1. & $\Delta$ & Ir & بازى واجراى نمايش & \\
\hline & r & . & . & . & r & جنيَيدن & \\
\hline & r & . & . & . & r & بختن & \\
\hline \multirow{4}{*}{ Irr } & 11 & 1 & ir & 1 & r & علاقه به تفكر & \\
\hline & q. & $r$ & r & . & $\Delta \Delta$ & بيان احساسات & $\hat{\sigma}$ \\
\hline & 9 & . & . & $\cdot$ & 9 & علايق شخصى را بيان كردن & के \\
\hline & 10 & $r$ & ir & . & . & سلامت و ايمنى & \\
\hline \multirow{3}{*}{ ror } & lof & f. & $\mu$ & ir & 91 & رابطه با ديخر ان & 3. \\
\hline & ar & 94 & 9 & r & 19 & درك ديخر ان & 5 \\
\hline & 4 & . & . & 9 & . & رعايت قوانين ومقررات & \\
\hline \multirow{4}{*}{$r .}$. & IFT & irA & $r$ & $\cdot$ & ir & ارتباط با خدا & \\
\hline & rی & if & . & . & if & ييامبران و امامان & $q$ \\
\hline & r^ & 19 & . & $r$ & 9 & احكام دينى (نماز-قران .. & $\underline{1 n}^{9}$ \\
\hline & 1 & . & . & $\cdot$ & 1 & اماكن مذهبى & \\
\hline \multirow{2}{*}{ ra9 } & irA & $\wedge$ & rı & rf & 68 & شناخت گياهان و حيوانات & $\rightarrow$ \\
\hline & 191 & 11 & $\Delta q$ & $r$ & 90 & شناخت طبيعت و گر دش & 13 \\
\hline \multirow{2}{*}{. } & ${ }^{\circ}$ & . & & . & ${ }^{\circ}$ & بخاطر داشتن ترانهها و سرودها & 3 \\
\hline & · & . & $\cdot$ & . & $\cdot$ & آو از خواندن & as \\
\hline rew & rew & $\Delta v r$ & rar & ak. & wr & جمع كل & \\
\hline
\end{tabular}

هستى گر ايانه و و9Y مورد به هوش طبيعت گر ايانه توجه شـده اسـت و به

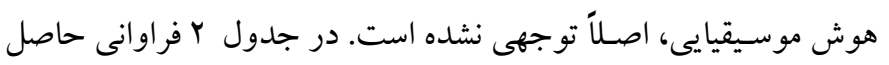

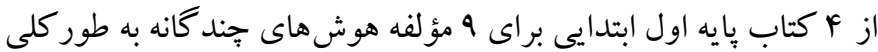

نشان داده شده است.
مندرجات جدول انشـان مىدهد كه از مجموع MFVV مورد توجه به

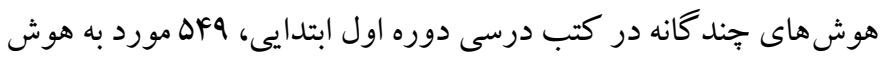

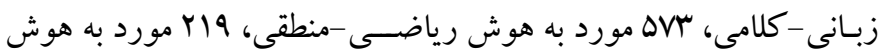
تصويرى-فضايى، YDA مورد به هوش جنبشى- بدنى، بrا مورد به هوش

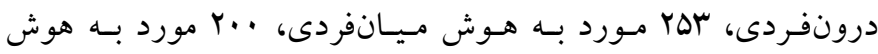

جدول r: فراوانى حاصل از ع كتاب هايه اول ابتدايى براى 9 مؤلفه

\begin{tabular}{|c|c|c|c|c|c|c|c|c|c|}
\hline موسيقيايى & طبيعت كرا & هستى & ميان فردى & درون فردى & جنبشى-بدنى & تصويرى-فضايى & رياضى - منطقى & زبانى -كلامى & كتب درسى \\
\hline & 19 & 101 & 1.4 & $r v$ & if & $\mu$ & ir & 199 & قرآن \\
\hline . & $\wedge V$ & $r$ & rr & rq & vr & Pl & 119 & $r F$ & علوم ع \\
\hline . & rv & $r$ & rr & 1 & $v r$ & 91 & rap & $1 r q$ & رياضى \\
\hline . & 194 & rq & $\Delta F$ & 91 & 99 & $\Delta q$ & $\wedge$. & IAV & فارسى \\
\hline . & raq & $r .$. & ror & rr & rOA & riq & $\Delta v r$ & $\Delta F q$ & جمع كل \\
\hline . &.$/ 119$ & $\cdot / \cdot 11$ & $\cdot / 1 \cdot r$ &.$/ . \Delta r$ &.$/ 1.4$ & $\cdot / \cdot M$ & 年/ & $\cdot / r r$. & درصد فراوانى \\
\hline
\end{tabular}

كتاب هاى پايه اول ابتدايى، هF\&ه مورد به هوش زبانى - كلامى، سله مورد

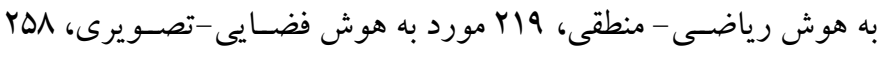

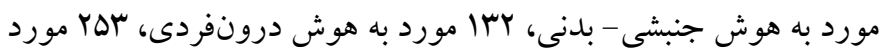

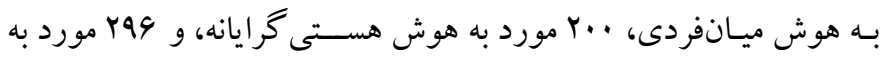

نتـايج جدول Y نشــان مىدهد كه از بررسـى كل ب كتاب بايه اول ابتدايى، مؤلفه هوش رياضى - منطقى با سلاه مورد، بيشترين فراوانى را به خود اختصاص داده و كمترين مقدار مربوط به هوش موسيقيايى با صفر

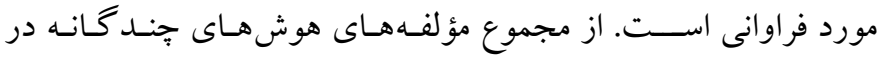


9 مؤلفه حاصـل از \& كتاب اول ابتدايى بر اسـاس روش آنترويى شـانون كزارش شده است.
هوش طبيعت گرايانه توجه شـده و به هوش موسـيقيايى اصسلاً توجه نشده اسـت. در جدول ب دادههاى بهنجار شده (Pij) هوش هاى جند گانه براى

جدول r: دادههاى بهنجار شده (Pij) حاصل از ع كتاب اول ابتدايى براى 9 مؤلفه

\begin{tabular}{|c|c|c|c|c|c|c|c|c|c|}
\hline موسيقيايى & طبيعت 1 ر & هستى & ميان فردى & درون فردى & جنبشى - بدنى & تصويرى -فضايى & رياضى-منطقى & زبانى_كلامى & كتب درسى \\
\hline . & .1 .94 & ./Vq. &.$/ 411$ & $\cdot / r \Lambda$. &.$/ \Delta F$ & ./IFY & r & $\cdot / r \Delta q$ & قر آن \\
\hline . & - /raq &.$/ .10$ &.$/ \mathrm{V}$ &.$/ 192$ & - /YVQ & . /AAV & טTr/. & .1 .94 & علوم \\
\hline . & $\cdot / \Delta \Delta$. & $\cdot / \backslash \Lambda$. & צזr/. & $\cdot / \Delta r$. & - rAA & - /YDQ & ./lf. & . MKF & فارسى \\
\hline
\end{tabular}

است، از اهميت بيشترى برخوردار است. در جدول \& مقدار بار اطلاعاتى، ضـريب اهميت، و رتبه حاصـل از كتب درسـى پيايه اول بر اى نه مؤلفه

هوش هاى جند گانه گز ارش شده است.
يس از نرمـالســازى دادههـا با اســتفاده از فرمول مرحله دوم روش شـانون، مقدار بار اطلاعاتى و ضريب اهميت هر يكك از مؤلفهها به دست آمده است. للام به ذكر است كه هر مقوله كه داراى بار اطلاعاتى بيشترى

جدول ع: مقدار بار اطلاعاتى، ضريب اهميت، و رتبه حاصل از كتب درسى پايه اول براى نه مؤلفه هوشهاى جند كانه

\begin{tabular}{|c|c|c|c|c|c|c|c|c|c|}
\hline موسيقى & طبيعت كرا & هستى كرا & ميان فردى & درونفردى & جنبشى-بدنى & تصويرى-فضايى & رياضى -منطقى & زبانى -كلامى & سطوح \\
\hline . & $\cdot / \mathrm{VNI}$ & $\cdot / F F A$ & ./А९४ & ./VG. & ./^৭r &.$/ 941$ & $\cdot / \mathrm{WVI}$ & .1942 & مقداربار اطلاعاتى Ej \\
\hline . &.$/ \mathrm{TV}$ & $\cdot / \cdot n$ & . /1FG & . /TrF & . /1FG & $\cdot /$ / QF &.$/ \mathrm{TV}$ & $\cdot / 1 \cdot 4$ & ضريب اهميت Wj \\
\hline$\checkmark$ & $r$ & 4 & r & f & r & 1 & r & $\Delta$ & رتبه \\
\hline
\end{tabular}

منظر توجه به هوشهاى جند كانه، جنين به نظر مىرسد كه در كتب مورد بررسى از ميان نه مؤلفه هوش هاى جند كانه، به هوش رياضى - منطقى از نظر فراوانى بيشتر توجه شده و بر هوش موسيقيايى اصلاً توجه نشده است، اما يُ از تفسـير دادهها و محاسـبه ضـريب اهميت در مرحله سوم روش شـانون، نتايج به دسـت آمده نشـان دهنده بار اهميتى متفاوتى بوده است، بهطورى كه هوش تصــويرى-فضــايى در رتبه اول، هوش ميانفردى و جنبشـى - بدنى در رتبه دوم، هوش رياضسى - منطقى و طبيعت گر ايانه در رتبه سوم، هوش درونفردى در رتبه جهارم، هوش زبانى -كلامى در رتبه ينجم، هوش هسـتى گرايانه در رتبه شـشــم، و هوش موسـيقيايى در رتبه هفتم قرار كرفتهاند. اين يـافتههــا از لحاظ تأكيد مواد آموزشــى بر مؤلفههاى هوش هاى

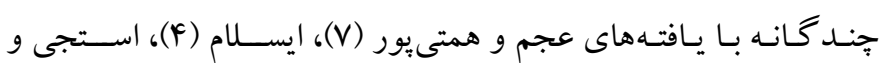
نفيسـى(IN) و كوبان و دوباز (YY) همسـو اسـت. بررسـى بهعمل آمده از كتـابـهـاى يـايـه اول ابتدايى نشــان مىدهد كه به مؤلفه هاى هوش هاى جند كانه بهطور متناسـب توجه نشـده اسـت، به طورى كه ميزان فراوانى هوش موسـيقى صـفر بوده اسـت؛ در حالى كه دامونت، سيورنيا، فرون و
نتـايج جــدول F نشـــان مى مهـد در محتواى كتابـهاى درســى اول ابتدايى، هوش تصويرى - فضايى با ضريب اهميت (IDF/ •) در رتبه اول، هوش ميان فردى و جنبشــى - بدنى با ضــريب اهميت (F4 / • در رتبه دوم، هوش رياضسى - منطقى و طبيعت كر ايانه با ضسريب اهميت (I Y /.) در رتبـه ســوم، هوش درون فردى بـا ضــريب اهميت (MFF / • در رتبه جهارم، هوش زبانى - كلامى با ضـريب اهميت (F ( \& •) رتبه ينجم، هوش هستى گر ايانه با ضريب اهميت (سل •/ •) در رتبه ششم، و هوش موسيقيايى بـا ضـــريسب اهميـت ( • در رتبه هفتم قرار دارند؛ بنابر اين مى توان نتيجه كرفت كه ضــريب اهميت مؤلفه هاى هوش هاى جند كانه در كتابهاى درسى يايه اول ابتدايى، يكسان نيستند.

\section{بحث و نتيجه تيرى}

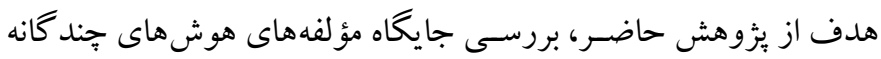
در كتـب يـايسه اول ابتــايى بوده اســـت. اين ئزوهش وجود نسه مؤلفـه هوشهـاى جنــــانـه را بـه روش تحليـل محتو ا در كتـابـهاى يايه اول ابتدايى بررسـى كرد. با توجه به تحليل كتب درسـى بايه اول ابتدايى از 
دنياى ييرامون، و ارزش ها را به آنها بدهد و در آنها اميد و آرامش ايجاد

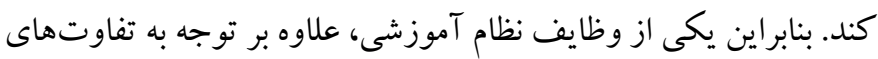

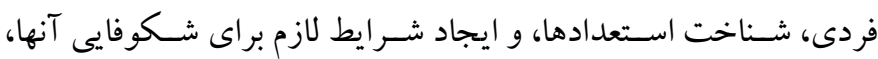
اسـتفاده از روش هاى خلاقانه و هدايت افراد به رشــتهاى تحصـيلى و مشـــاغل مرتبط بـا هوش غالب آنان اســت. بدين ترتيب توجه به نظريه

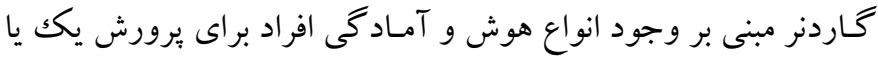

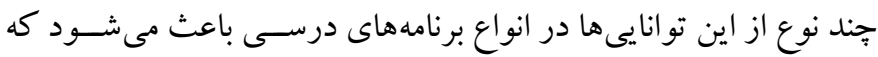

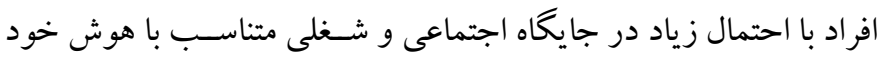

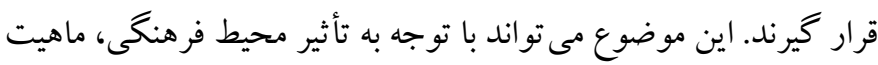
و عوامل مؤثر بر هوش، در يِيشــبرد علمى و حفظ ســلامت افراد جامعه، مورد توجه سياست گزاران آموزشى، شغلى، و بهداشتى قرار گيرد ( •r).

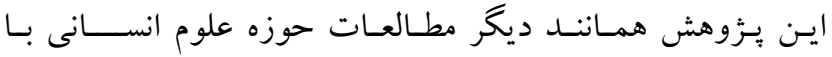
محدوديت هايى همراه بوده است. يافتهاى اين بزروهش محدود به تحليل

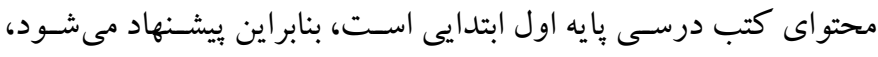

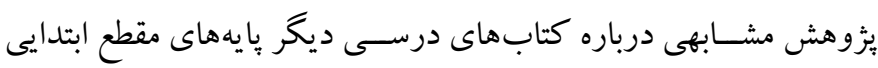

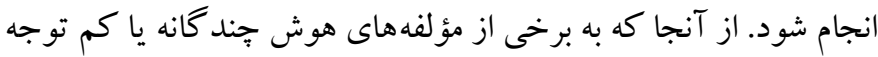

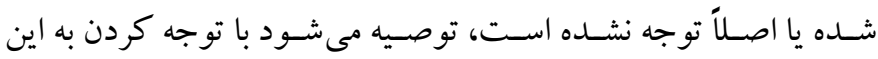

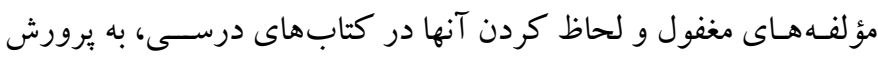

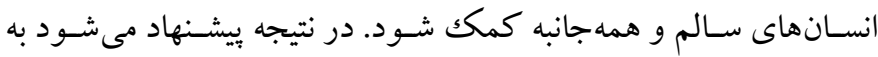

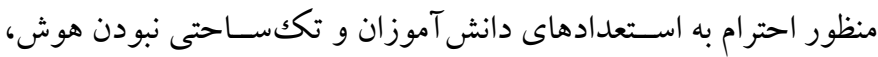

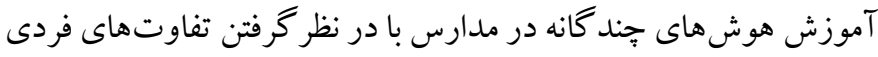

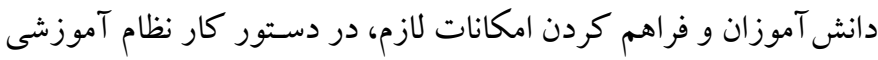
قرار گيرد.

تشكر و قدردانى: اين مقاله برگرفته از رساله دكتراى تخصصى به تاريخ ثبت

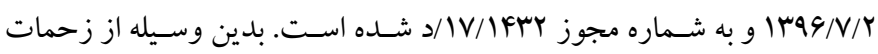

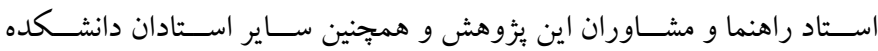
علومتربيتى و روانشناسى دانشكاه تبريز، قدردانى مى وشود.

تضاد منافع: لازم به ذكر است كه اين يُروهش براى نويسند كان مقاله هيج گونه

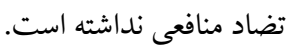

ونهورن (YN) موســيقى را ابزارى منـاســب براى تربيـت ذوق در دوره ابتدايى معرفى كرده و استفاده از آن رانه تنها وسـيلهاى براى لذت بردن

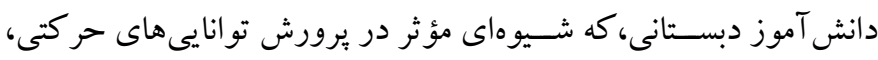

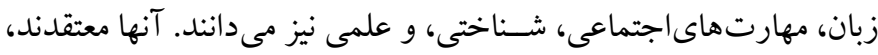

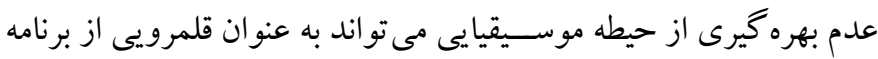
درسى مغفول در نظام برنامه درسى و غير رسـمى قلمداد شـود. در همين

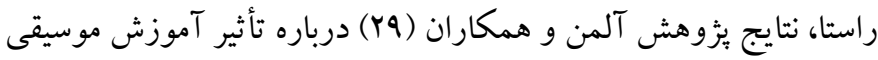

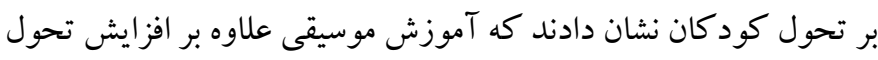

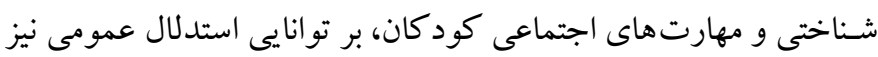
تأثير گذار بوده است. همجِين بررسـى بهعمل آمده از يُزوهش حاضـر نشــان مىدهد كه

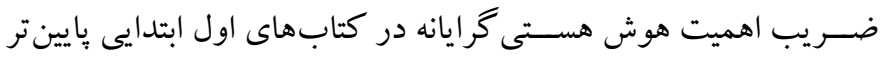

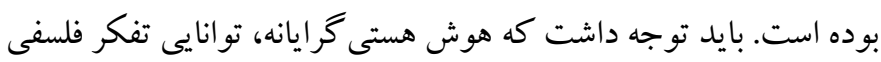

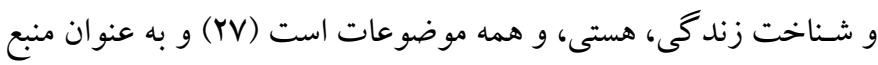

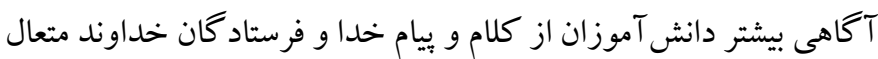

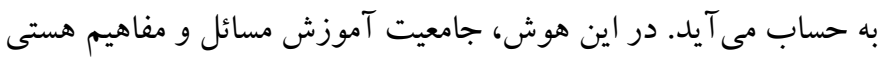

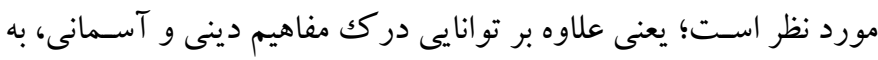

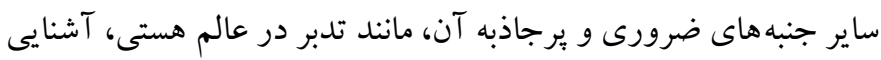
بـا امـامان، يِامبران، زيبايى هاى هســتى، و ايجاد انس با خحداوند متعال از

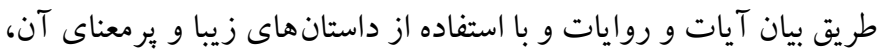
مورد نظر اسـت. در نتيجه شايسته است كه در تدوين برنامهاى درسى به صورت رسمى و غير رسمى به اين نوع هوش، اهميت زيادى داده شود.

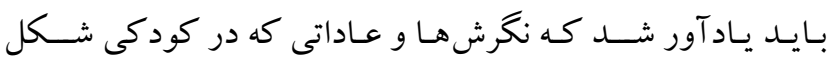
مى گيرند، درتصـميم گيرى هاى دوران بزر گسـالى نقش بسيار مهمى ايفا

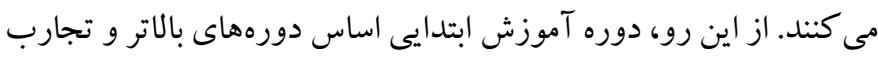

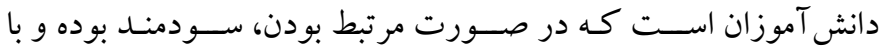

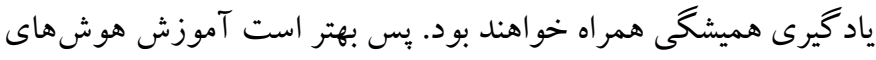

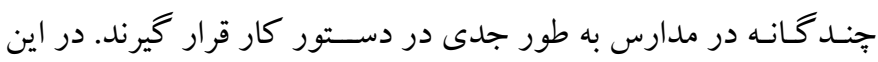

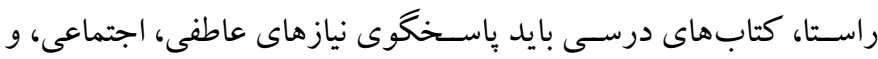
ارضاى حس كنجكاوى دانش آموزان بوده و امكان شناخت للازم از خوده، 


\section{References}

1. Gharibi H, Aslani J, Abdolmaleki M. Effectiveness of science education teaching based on multiple intelligence theory on creativity in 5 grade elementary school girl students. Research in Curriculum Planning. 2018; 15(56): 61-74. [Persian]. [Link]

2. Mayer JD, Panter AT, Caruso DR. A closer look at the test of personal intelligence (TOPI). Pers Individ Dif. 2017; 111: 301-311. [Link]

3. Constantinescu R-S. The theory of multiple intelligences-applications in mentoring beginning teachers. Procedia Soc Behav Sci. 2014; 116: 33453349. [Link]

4. Islam N. Survey of literature on the relationship between learners' multiple intelligences and academic achievement. International Journal of Research in Social Sciences. 2019; 9(3): 353-367. [Link]

5. Gardner H. Frames of mind: The theory of multiple intelligences. Edición: 3. New York: Basic Books; 2011, pp: 130-135. [Link]

6. Mehrmohammadi M. Speculative essays in education. Tehran: Tarbiat Modares University Press; 2014, pp: 361-383. [Persian].

7. Ajam AA, Hemmati Poor O. The relationship of multiple intelligence and health literacy of health students in Gonabad UMS, 2017. Journal of Community Health Research. 2018; 7(1): 48-56. [Persian]. [Link]

8. Cherry K. Gardner's theory of multiple intelligences [Internet]. Verywell Mind. [Cited 2020 May 15]. Available from: [Link]

9. Hajhashemi K, Akef, Anderson N. The relationship between multiple intelligences and reading proficiency of Iranian EFL students. World Applied Science Journal. 2012; 19(10): 1475-1483. [Link]

10. Tezer M, Ozturk R, Ozturk C. A case study on the effect of geometry course in high schools by multiple intelligence theory. Procedia Soc Behav Sci. 2015; 197: 31-37. [Link]

11. Cervera EL. Learning styles and multiple intelligences in the teaching-learning of Spanish as a foreign language. Enseñanza \& Teaching: Revista interuniversitaria de didáctica. 2015; 33(2): 79-103. [Link]

12. Abolfazli Khonbi Z, Gholami J. Iranian EFL studentteachers' multiple intelligences and their self-efficacy: Patterns and relationships. Issues in Language Teaching. 2015; 4(1): 27-47. [Link]
13. Rezvani R, Amiri T. Multiple intelligences representation in Iranian official ESP textbooks: A content analysis study. Journal of New Approaches in Educational Administration. 2014; 4(16): 189-200. [Persian]. [Link]

14. Sulim GHSA. Prediction of the correlation between the strategies of the teaching methods and the multiple intelligence of some graduate female students at Imam Mohammad Ibn Saud Islamic University. Procedia Soc Behav Sci. 2012; 47: 1268-1275. [Link]

15. Temur OD. The effects of teaching activities prepared according to the multiple intelligence theory on mathematics achievements and permanence of information learned by 4 th grade students. Int $\mathrm{J}$ Environ Sci Educ. 2007; 2(4): 86-91. [Link]

16. Ofrim-Stăncună L-A. A multiple intelligences approach 3: Cambridge assessment. Procedia Soc Behav Sci. 2015; 203: 90-94. [Link]

17. Tithi UM, Arafat Y. Exploring the challenges of application of multiple intelligences theory in teaching learning process at primary level in Bangladesh. The International Journal of Social Sciences. 2012; 15(1): 31-39. [Link]

18. Estaji M, Nafisi M. Multiple intelligences and their representation in the EFL young learners' textbooks. International Journal of Research Studies in Language Learning. 2014; 3(6): 61-72. [Link]

19. Ameenee M, Tamanaa'eefar MR, Ameenee S. The theory of multiple intelligence and its implications for designing learning opportunities and experiences. The Journal of New Thoughts on Education. 2009; 5(4): 91-106. [Persian]. [Link]

20. Meltzer L, Krishnan K. Executive function difficulties and learning disabilities: Understandings and misunderstandings. In: Meltzer L, editor. Executive function in education: From theory to practice. New York: The Guilford Press; 2007, pp: 77105. [Link]

21. Rile LG, Opulencia MJC-, Decenorio NM, Tan NL. Multiple intelligences of students with learning disabilities: Its implication for business curriculum development in United Arab Emirates. Procedia Economics and Finance. 2015; 23: 894-898. [Link]

22. Coban S, Dubaz İ. The relationship between active learning models in music lessons in elementary schools and multiple intelligence areas. Procedia Soc Behav Sci. 2011; 28: 684-690. [Link]

23. Abdi A, Soleymani H, Rezai B. A study of effect of multiple-intelligence-based instruction on learning progress and attitude towards general English course. 
جايگاه برنامه مبتنى بر هوش هاى جند گانه در كتب درسى دوره اول ابتدايى

Educational Psychology. 2013; 9(27): 114-133. [Persian]. [Link]

24. Sarmad Z, Bazargan A, Hejazi E. Research methods in behavioral sciences. Tehran: Agah Publication; 2016, pp: 195-197. [Persian].

25. Shannon CE. A mathematical theory of communication. Bell System Technical Journal. 1984; 27(3): 379-423. [Link]

26. Azimi M, Adib Y, Matlabi H. Conformity of hygiene education and health promotion course content of the six grade of elementary school books with the health system goals. Journal of School of Public Health and Institute of Public Health Research. 2017; 15(1): 8396. [Persian]. [Link]
27. Fleetham M. Pocket PAL: Multiple intelligences. A\&C Black; 2014, pp: 30-32. [Link]

28. Dumont E, Syurina EV, Feron FJM, van Hooren S. Music interventions and child development: A critical review and further directions. Front Psychol. 2017; 8: 1694. [Link]

29. Alemán X, Duryea S, Guerra NG, McEwan PJ, Muñoz R, Stampini M, et al. The effects of musical training on child development: A randomized trial of el Sistema in Venezuela. Prev Sci. 2017; 18(7): 865878. [Link]

30. Rezakhani S. Construction and standardization of Gardner's multiple intelligence test1. Quarterly of Educational Measurement. 2014; 5(18): 179-206. [Persian]. [Link] 